\title{
EUROPEAN SECURITY CAPABILITIES IN THE REGION OF THE WESTERN BALKANS IN THE BEGINNING OF THE TWENTY-FIRST CENTURY
}

DOI: $10.2478 /$ seeur-2014-0013

The London Conference of Ambassadors held in the second decade of the $20^{\text {th }}$ century indicated a new path for the Balkan states for the next one hundred years. The political breakthroughs in the region at the turn of the $21^{\text {st }}$ century, including the fall of regimes in Serbia and Croatia, Kosovo's road towards independence and regional integration into the European Union and North Atlantic Treaty Organization, are now determining the path for the upcoming decades. Both the change of 1913 and the one at the beginning of the 21st century were initiated with armed conflicts and left the people of the region with tremendous experiences to deal with and painful lessons to be learned. Those lessons though, mainly due to increasing international political exchange and decreasing geographical distance between the European capitals, are to be learned and applied today not only by the policy makers in the region, but also - if not primarily - by the crucial political, and particularly security actors in Europe and overseas. This results mostly from the fact that the integration of the Western Balkan countries with the European security system or security complex ${ }^{1}$ is a real, ongoing process constantly progressing in numerous sectors and advanced enough not be stopped or reversed easily.

The aim of this paper is to highlight the need of a proactive and multisectoral strategy of inclusion of the Western Balkan countries into the European security system based on positive assumptions. In order to avoid the "Balkanism" " narrative on the region perceived as a natural source of security

1 The limited length of the paper does not allow me to elaborate on the problem of security system/complex in Europe, however, I assume that such exists. See more: Barry Buzan and Ole Waever., Regions and Powers: The Structure of International Security (Cambridge: Cambridge University Press, 2003).

2 Maria Todorova, Imagining the Balkans (New York: Oxford University Press, 1997). 
threats, I make an attempt to answer the question on what positive components either can be or should be seen as the crucial Western Balkan security capabilities and how can they contribute to the creation and development of the European security in the $21^{\text {st }}$ century. The main argument of the paper assumes strong interdependence and correlation between geopolitics and capabilities that should constitute a fundament for development of European security policies. I argue that the European Union and NATO should develop a specific strategic culture based on the two above-mentioned elements geopolitics and capabilities - together with historical experiences and common values system. Only coherent and common strategic and geopolitical thinking in Europe, with the Western Balkans included, will contribute to the increase of the level of European security. Out of the four factors ${ }^{3}$ these are the capabilities that require an in-depth country specific analysis and these are geopolitical considerations that need political will to be recognized as a still valid element of strategic security games in the Euro-Atlantic space.

\section{When a change becomes a constant}

At the 1913 Conference of London six great powers agreed on eleven points that provided the basis for the international recognition of Albanian independence. While analyzed today the impression of their evident resemblance to the UN Resolution 1244 (obviously with the crucial exception of the status issue of Kosovo) and other modern international provisions on the Western Balkan countries, particularly on Kosovo and Bosnia and Herzegovina, cannot be avoided. Control, mentoring and monitoring of civil administration and financial structures, assurance of public order and security by a newly established international commission and international organizations as predicted by the Treaty of 1913 could be easily read as EULEX or KFOR mandates. This observation naturally brings to mind the argument on the fact that neither geography, nor geopolitics really change and the region remains a place where the international community tends to maintain its presence and control. However, although the ongoing - or at least highly possible - shift of the Western Balkan countries from being security consumers to security providers is a fact and the world is facing such enormous geopolitical changes as the 19 April Brussels Agreement, which might be the greatest geopolitical change in the region after the dissolution of Yugoslavia, Western policy makers still tend to perceive the region as a

\footnotetext{
3 Asle Toje, "Strategic Culture as an Analytical Tool. History, capabilities, geopolitics and values: the EU example", Western Balkans Security Observer, 14 (2009), 4.
} 
natural source of threats and ethnic hatred. This also significantly contributes to empowerment of another component of the never changing international approach to the region, namely the strong focus on the negative dimension of security and on military security in security policies design ${ }^{4}$.

Geopolitics has significantly lost in popularity in Western Europe in the course of the past two decades; it is worth noticing though that the Balkan region represents a specific exception in that matter. The popular geopolitics (media and social discourses) and the structural geopolitics (understood as contemporary geopolitical tradition) remain relatively strong and follow the conservative, negative pattern in political and societal discourses on the Balkans both in the Western Balkan countries themselves and in the West. However, the formal geopolitics (geopolitical culture of traditional geopolitical actors) and the practical geopolitics (actual practice of geopolitical strategy $)^{5}$, both crucial for the political developments, are not being developed either in the Western Balkan countries, or in the EU and NATO states, with a minor exception of the US. This results in constant reproduction of conflict narrative and domination of the geopolitical and security discourse and practice by resentments, prejudices and cliché judgments.

All of the Western Balkan countries have taken major steps towards the European Union and NATO. The membership criteria have been clearly formulated by both organizations, declarations of political will and on the importance of the process, such as the Thessaloniki Declaration, European Security Strategy or the NATO Summits Declarations have been signed by the heads of the key players in the field of the European security. Moreover, more and more binding agreements aimed at preparation of the countries for a full integration are being signed and implemented, including the Partnership for Peace agreements, Membership Action Plans or the Stability Pact for South Eastern Europe. Important political steps, such as the Security Sector Reforms, ongoing dialogue between the Republic of Serbia and Kosovo, war crime trials or the negotiations on the state name of Macedonia, have been

4 The Balkan region was mentioned seven times in the 2003 European Security Strategy. In six of those seven cases the region has been recalled in reference to the past as an example of great European success in the field of peacekeeping and peacebuilding. In the last case the region represents the most prominent example of countries and regions that pose the biggest threats to Europe resulting from organized crime, mainly drugs and human trafficking. European Council, A Secure Europe in a Better World. European Security Strategy (Brussels: European Council, 2003), 5.

5 Gearóid Ó Tuathail, "Understanding Critical Geopolitics: Geopolitics and Risk Society," in Geopolitics, Geography and Strategy, eds. Colin S. Gray and Goeffrey Sloan (London: Frank Cass, 1999), 109-123. 
made also by the Western Balkan countries themselves. And even though there are still some serious obstacles present on the integration path, mainly of a political and economic nature, the processes continue. None of the actions taken either by the countries in the region, or by the European security actors though, even attempts to shape a coherent idea, a strategic view on what role the Western Balkan countries should have in the creation of the Euro-Atlantic security space.

Both the European Union and NATO obviously lack a clear vision of the role of the Western Balkan region in Europe and particularly in its security system. The ongoing integration together with the absence of strategic thinking create a danger of destabilization of the whole European security complex. Most European analysts and stakeholders who take into consideration the relation between the security issues and the questions of the Western Balkans focus on the threats coming from the Balkan Peninsula and hardly ever make even a slight attempt to indicate the possible contribution the countries can have on the European security system. An analysis of a positive nature, focused on the regional capabilities and specific character of the countries of the region can fulfil important political, societal and economic functions. The above is particularly important when faced with the development of NATO from a military alliance to a security regime, the shift of the European Union from an economic integration project to a political one (covering also foreign affairs and security issues), as well as deepening and widening the horizon of their activities. The Western Balkans case could be an important point in the newly designed security architecture. At this point the Western Balkans demonstrate only a geopolitical gap, somewhere between the West and the East, the North and the South, the past and the future and both NATO, US and EU policies are stuck in the 90s and do not follow any roadmap designed along the axes of the contemporary reality. Further enlargements themselves will not increase the level of security and, as it has been proven by the enlargements in the late 90s and early 2000s, will not necessarily strengthen the organizations. Therefore, only active, offensive and positive political actions taken on the basis of a clear geopolitical and geostrategic security concept may contribute to the system, especially at the moment when Europe is being faced with serious economic and political challenges.

\section{Integrating the security system - when and how?}

The difficulty assessing the potential contribution of the Western Balkan states results not as much from methodological issues, as it does from the 
political ones. The unpredictability of the regional developments together with the uncertain temporal dimension of the integration processes make the estimation of the capabilities particularly problematic. Therefore, the future of the integration of the Western Balkan countries with the European security complex requires several possible scenarios to be investigated in order to create a sustainable European security environment. For the aim of this paper I find three of them worth considering. In the first scenario, the integration process will go on as it is now with the assumption, that either integration per se will create a desired security environment both in the region of the Western Balkans and in the whole European security complex, or that integration is a natural consequence of stabilization and there is no other possible future for the region. In the second variant, the integration process will go on following the dynamics of the development, political will and capabilities of each of the Western Balkan states individually. Neither the EU nor NATO will aim to build a region-wide Western Balkan partnership or to treat the states as members of a bigger whole. And finally in the last one, the process will go on, whereas the region-wide cooperation and partnership in the Western Balkans will be considered as crucial for further integration and vital effort should be put to create a mutual understanding, respect and value-based cooperation between the Western Balkan states.

Elements of transition - stabilization - integration dynamics, although strongly correlated, are not based on causality and do not proceed simply one after another, especially when such an extremely differentiated case like the Western Balkans is considered. Likewise the three-phase dynamics, stabilization - through - integration approach is one of rather normative than positive nature. The stabilisation agenda and the belief that the political and security challenges of the region will be resolved by the integration of the Western Balkan countries with the EU has dominated the European security thinking so far. In the context of the London Conference the same point of view is frequently represented in the region itself in reference to the Albanian issue. However, as far as stabilizing the neighborhood is an important issue, this does not constitute a (geo)strategic vision of integration and successful integration cannot be perceived as a natural effect of successful transition and stabilization. All three elements of the dynamic should be supported and stimulated in order to build a secure and stable Europe.

The two scenarios focused on the problem of intraregional cooperation or partnership seem to be particularly relevant and interesting at the moment when we are facing the fact of Croatia's EU membership on the one hand and serious internal challenges in several other states of the region, particularly in Bosnia and Macedonia, on the other one. The integration concept based on the assumption that only a unified Western Balkan region is able and allowed to 
fully integrate with the EU and NATO will most probably result in a strong dependence of the countries on the international structures. The European Union has unintentionally resigned itself to this idea when the common Thessaloniki-like voice from Brussels fell silent after the financial and institutional crisis of 2008. It created by chance a possibility of development of state - EU and state - NATO dynamics driven by interests of both sides. Obviously it still does not exclude possibilities of cooperation within the region; however it does not assume it is a sine qua non in the integration process. The identification and development of the niche capabilities or just the capabilities that may be developed better or in a more efficient way by the Balkan states then they may be in Western Europe, should be viewed and appreciated as a crucial element of security integration from two different perspectives, defined by the vital interests of the Euro-Atlantic community on the one side, and of the individual Western Balkan states on the other.

\section{Contribution to the security system - why and what?}

The analysis of the security capabilities in the Western Balkan region shows that the integration must not necessarily proceed "to the end" and some other forms of co-operation excluding full membership can be - at least in the short and middle term perspective - more beneficial for both sides. Moreover it proves that the relevantly weak Western Balkan states are potential brilliant players of specific security roles in the European security complex and may be used as suppliers of particular goods and services which will both strongly contribute to the shape of the European security and to the national security systems of the states.

The Western Balkan countries are extremely specific security actors in the European complex and the factors which create their extraordinary security capabilities should be taken into detailed consideration in the process of European security policy planning. Due to the limited length of this paper, only the most relevant ones can be highlighted here. First, the Western Balkan countries are the only European countries which have experienced wars and armed conflict on their territory in the post Cold War era. Second, they are the only European countries that have conducted wars and armed conflicts of the nature of new wars ${ }^{6}$. Third, they are the only European countries which have experienced wars and armed conflict in the post Cold War era as sides and not as a third party. Fourth, the only European Muslim countries are placed in the

\footnotetext{
6 Mary Kaldor, New and Old Wars: Organized Violence in a Global Era (Stanford, CA: Stanford University Press, 1999).
} 
region and at the same time they are one of the most pro-Western Muslim societies in the world. Fifth, the geopolitical location of the region and its past experiences make it an important variable in the relations between the EU, U.S. and Russia. Sixth, the geopolitical placement of the region makes it a perfect gas and oil transit way and can significantly contribute to the diversification of European energy supply. Seventh, the transitional experiences in the Western Balkan countries are of a unique value since they were conducted in simultaneously post-conflict and post-authoritarian environments. And finally eighth, the very recent historical experiences and strong military tradition create a very positive social environment for investments in the military sector and development of national, regional and sub-regional defence and security systems.

Small and unconsolidated Balkan countries will never play a strategic role in the security system, their armed forces are small, underinvested and have old type equipment at their disposal; however, they need to play a role, should not be left just as members and the role should be possibly well defined. Their membership, although important per se from a geopolitical point of view, may contribute much further to the stability of the whole European complex and of the region itself, though, this will not happen automatically. By now, to a very limited scope though, this is the field of hard power and security perceived from the narrow perspective that is officially recognized by the EU and NATO as the capabilities that should be developed and responsibilities that should be covered by the Western Balkan countries. Some of them are already carried out in the operations in Iraq and Afghanistan, as for instance the combined Albanian-Croatian-Macedonian military medical team ${ }^{7}$. Such activities do indeed constitute a proper response to the requirement of identification and development of niche or at least specific capabilities, but they do not make much use of the unique capabilities that the Balkan states already possess despite from the obvious advantage that the great majority of the military personnel in the region are combat veterans, experienced in the battlefield. However, such examples as the extremely successful activities of special forces units from Macedonia - Wolves and Scorpions - in the Middle East should highlight the way the processes should follow. As the recent reports concerning the Kosovo and Bosnian citizens' involvement in Syria prove, to date these are mainly private military companies and mercenary organisations that take great advantage of the local experience, expertise and approach towards military combat.

7 NATO Parliamentary Assembly, The Three Adriatic Aspirants: Capabilities and Preparations, Committee Report 165 DSCFC 07 E rev 1 (Brussels: NATO Parliamentary Assembly, 2007). 
In reference to hard power and the narrowest security perspective, a historical analysis and a strategic review of the security sectors in the investigated countries leads to a conclusion that the Balkan expertise, experience and understanding of the substance may play a crucial, or at least significant, role in several fields of security activities, including: special forces and special operations, demining, explosive ordnance disposal, rapid reaction, military police, IEDs (Improvised Explosive Devices) disposal, surface to air/air to surface support, as well as issues related to the functioning of private military companies, private security companies and mercenaries. This is also the strategic understanding of the new wars' dynamics that is strongly underestimated as a part of the Western Balkans expertise.

The presence of Muslim countries and large Muslim communities in the region on the one hand, and special relations to several Middle East countries on the other one, create a perfect space for development of the European and Transatlantic approach towards and relations with the Muslim world and strengthening soft power in this area. The special relations of some of the Balkan states to Turkey (strategic and economic liaisons of Serbia, cultural liaisons of Bosnia and Herzegovina, Albania and Kosovo) and presence of Mujahedeen community in Bosnia and Herzegovina together with their experience with training and multilateral, often confidential co-operation with numerous parties and non-parties engaged in the conflicts in the Balkans in the 90s, as well as the relations to Iran, Pakistan and Saudi Arabia developed mainly by Bosnia and Herzegovina, but also by the Albanian and Kosovo authorities during the wars in the 90 s, seem to be potentially particularly appealing for the European security community.

Energy security remains one of the most burning questions for Europe and diversification of gas and oil suppliers is a must that everybody is aware of. The region of the Western Balkans has a huge potential in reference to diversification of European energy supply as has already been demonstrated by such projects as the LNG Terminal on the Croatian island of Krk. However, the problems with infrastructure and control make the region itself insecure in the terms of energetic security and therefore the possibilities can be considered only in a long-term perspective.

The transitional experiences in the Western Balkan countries are of a unique value since they were conducted in simultaneously post-conflict and post-authoritarian environments. The know-how is invaluable and as the Central and Eastern European examples do serve in the world as best practice examples for political and economic post-authoritarian transformation, the Balkan experiences seem to be more valuable when a post-conflict systems are considered. Moreover, the Security Sector Reforms in the Western Balkan countries and particularly the successful implementation of democratic 
control and civilian overview over the military forces should be perceived as a great asset of the region and experience to be shared all over the world.

Despite of the already mentioned issues, when reviewing the European security in a broad sense several other field of activities should be underlined as the ones that constitute significant opportunities for creation and development of elements supporting the sustainable security environment. The meaning of the river Danube can be one of the prominent examples. Its great economic potential and environmental meaning of both positive (trade, energy, etc.) and negative (black market for drugs, SALW, etc.) importance should be considered in terms of security and not economy only, as it has been developed so far by the European Union within the framework of the EU Strategy for the Danube Region ${ }^{8}$. The societal dimension of security is another component of the important and apparently underestimated capability of the Western Balkan countries. The non-appreciated civil war experiences are an invaluable source of knowledge on how to work with civilians, women and children, refugees and IDPs in conflicted, multi-ethnical and multi-religious societies.

\section{Security partners - a challenge for the future}

An analysis of a positive nature and attempts to identify and develop the security capabilities located in the region of the Western Balkans may not remain unrelated to the ones of negative nature. Although the European security system has never been as stable as it is now, one cannot forget about the negative dimension of security and significant - if not vital - threats that may result from making the new, fragile democracies rightful members of the international security community. A very clear example is represented by the development of the European Defence Equipment Market. The question on how the states with the highest number of illegal weapon in Europe and extensively involved in arms trafficking should function within the integrated market will remain open for years. However, as threats exist the strong political focus on them will not contribute to development of friendly security environment in Europe.

As demonstrated in this paper, the problem of security capabilities can be perceived in two ways, and both of them are relevant in reference to the Western Balkans. First, a capability can be understood as the direct

8 European Commission, European Union Strategy for Danube Region (Brussels:

European Commission, 2010). 
contribution that a country can make, so that the other members of the security system and the system itself can benefit from it. Second, it can be seen as a potential added value resulting from accurate policies towards the country/region, cooperation with them and instrumental use (however, not in a pejorative sense) of those policies in relation with third parties. Both approaches are extremely complex and complementary at the same time.

This paper addresses two strongly interdependent issues crucial for the security of the Western Balkan region and the wider European security complex. The geopolitics of the Balkans change constantly as the global power distribution evolves, and particularly as the concept of Europe and the West grows together with the subsequent EU and NATO enlargements. Given the strategic location of the region at the crossroads of political influences and cultural identities the region can neither be pushed out of European security space nor left as a laboratory where both the threats and counteractions are tested. The region as a whole needs to be equally involved in the security developments in the Trans-Atlantic area and has to contribute to the security system with its particularly specific capabilities. The Balkan countries constitute the closest and most obvious source of knowledge on new type wars, peacekeeping, reconstruction, and long-term peace- and state-building.

The shift of the Western Balkan countries from being security consumers to security providers is a fact. Therefore, as indicated above, an ill-considered and unstructured integration process lacking a strategic vision might shape a threat for the security of Europe as a whole. Supporting the development of well defined and detailed niche capabilities should be a focal point of all the integration processes and the niche capabilities and unique experiences should serve to support the development of both negative and positive, narrow and broad security in the system. Only such an approach will allow for the creation of a stable, sustainable and permanent security environment in the region of the Western Balkans, in Europe and in the whole Euro-Atlantic system. 


\section{Bibliography}

- Asle Toje, "Strategic Culture as an Analytical Tool. History, capabilities, geopolitics and values: the EU example", Western Balkans Security Observer, 14 (2009), 3-23.

- Barry Buzan and Ole Waever, Regions and Powers: The Structure of International Security (Cambridge: Cambridge University Press, 2003).

- European Commission, European Union Strategy for Danube Region (Brussels: European Commission, 2010).

- $\quad$ European Council, A Secure Europe in a Better World. European Security Strategy (Brussels: European Council, 2003).

- EU-Western Balkans Summit, The Declaration of Thessaloniki (Thessaloniki: EU-Western Balkans Summit, 2003).

- Fotios Moustakis, "Soft Security Threats in the New Europe: The Case of the Balkan Region", vol. 13 of European Security 12(2004): 139-156.

- Gearóid Ó Tuathail, "Understanding Critical Geopolitics: Geopolitics and Risk Society," in Geopolitics, Geography and Strategy, eds. Colin S. Gray and Goeffrey Sloan (London: Frank Cass, 1999), 107-124.

- Gilles Andreani, Christoph Bertram and Charles Grant, Europe's Military Revolution (London: Centre for European Reform, 2001).

- Maria Todorova, Imagining the Balkans (New York: Oxford University Press, 1997).

- Mary Kaldor, New and Old Wars: Organized Violence in a Global Era (Stanford, CA: Stanford University Press, 1999).

- Misha Glenny, The Fall of Yugoslavia: The Third Balkan War (London: Penguin, 1996).

- NATO Parliamentary Assembly, The Three Adriatic Aspirants: Capabilities and Preparations, Committee Report 165 DSCFC 07 E rev 1 (Brussels: NATO Parliamentary Assembly, 2007).

- $\quad$ Robert E. Hunter, "Enlargement: Part of a Strategy for Projecting Stability into Central Europe," vol. 43 of NATO Review 3(1995): 38.

- Slavoljub B. Šušić, Geopolitički košmar Balkana (Beograd: Vojnoizdavački Zavod, 2004).

- Solveig Richter, "Two at one blow? The EU and its quest for security and democracy by political conditionality in the Western Balkans", vol. 19 of Democratization 3(2012): 507-534. 
- Stanko Nišić, Globalna sila i bezbednost Balkana (Beograd: Vojnoizdavački Zavod, 2002).

- Susan Woodward, Balkan Tragedy: Chaos and Dissolution After the Cold War (Washington DC: Brookings Institution Press, 1995).

- Suzette R Grillota, Rebecca J Cruiseb and Valerie J D'Ermanb, "Developing security community in the Western Balkans: The role of the EU and NATO", International Politics 47(2010):62-90.

- The Future of Security Sector Reform, edited by Mark Sedra (ed.), (Waterloo: The Centre for International Governance Innovation, 2010).

- Thomas S. Szayna, NATO Enlargement 2000 - 2015. Determinants and Implications for Defense Planning and Shaping, Monograph Report 1243 (New York: Rand Corporation, 2001).

- United States General Accounting Office, Balkan Security. Current and Projected Factors Affecting Regional Stability, Briefing Report to the Chairman Committee on Armed Services, House of Representatives (Washington DC: United States General Accounting Office, 2000). 
Ida Orzechowska is a Ph.D. candidate at the Institute of Political Science of the University of Wroclaw, Poland, in political science and sociology. Her main research interests relate to international security, the Western Balkans and conflict studies. She recently completed a visiting fellowship at the Centre for the Study of the Balkans, Goldsmiths, University of London. She is currently based in Kosovo and developing her dissertation on the correlation between power distribution and stability in the Western Balkan region. Professionally involved in the Balkans for several years as an independent scholar, she regularly publishes analyses of the security dynamics in the region, i.a. in the quarterly news journal New Eastern Europe. 